\title{
The Dilemma of Masks During the COVID-19 Outbreak
}

Juan Chen, ${ }^{1} *$ Yong-Ran Cheng, ${ }^{2, *}$ Wen Wen, ',* Chunyi Wang, '* Jie Ni,' Jingjie Jiang,' Xinyan Fu,' Mengyun Zhou, ${ }^{3}$ Lan Ye, ${ }^{4}$ Zhong-Jun Ge, ${ }^{5}$ HanXia Tan, ${ }^{6}$ Mingwei Wang, (1D) Zhan-Hui Feng, ${ }^{7}$ Xingwei Zhang'

'Department of Cardiology, Hangzhou Institute of Cardiovascular Diseases, Affiliated Hospital of Hangzhou Normal University, Hangzhou, People's Republic of China; ${ }^{2}$ School of Public Health, Hangzhou Medical College, Hangzhou, People's Republic of China; ${ }^{3}$ Department of Molecular and Cellular Physiology, Shinshu University School of Medicine, Nagano, Japan; ${ }^{4}$ Basic Medical College, Guizhou Medical University, Guizhou, People's Republic of China; ${ }^{5}$ Department of Cardiology, The Fourth People's Hospital of Lin'an, Hangzhou, People's Republic of China; ${ }^{6}$ Department of Oncology, The Third People's Hospital of Hangzhou, Hangzhou, People's Republic of China; ${ }^{7}$ Department of Neurology, Affiliated Hospital of Guizhou Medical University, Guiyang, People's Republic of China

*These authors contributed equally to this work

Correspondence: Zhan-Hui Feng Affiliated Hospital of Guizhou Medical University, No. 28, Guiyi Street, Guiyang, People's Republic of China Email h9450203@I26.com

Xingwei Zhang

Hangzhou Institute of Cardiovascular

Diseases, Affiliated Hospital of Hangzhou

Normal University, I26 Wenzhou Road,

Gongshu District, Hangzhou, People's

Republic of China

Email hsdzxw@I26.com
Background: Many people have experienced novel coronavirus pneumonia since the beginning of the COVID-19 pandemic in Wuhan, China. The Chinese government has encouraged people to wear face masks in public places; however, due to the large population, there may be a series of problems related to this recommendation, including shortages of masks and lack of an optimal disposal method for used masks.

Objective: The purpose of this study is to understand the current status of mask shortages and used masks in China.

Methods: A questionnaire survey was designed to assess the current status of mask shortages and used masks. The differences among groups were analyzed with chi-square tests.

Results: The constituent ratio of those who reuse masks was $61 \%$. Obtaining masks from the drugstore was reported to be very difficult due to high demand and short supply, and approximately $1 / 3$ of the respondents purchased expensive masks. Most people know how to properly handle used masks, and only $7 \%$ of them casually discard masks. However, $50 \%$ of respondents have seen others throw away used masks at will. A further subgroup analysis showed that respondents in Central China tended to use masks repeatedly, as did medical personnel. Females, people living in the central region, and medical personnel may find it more difficult to purchase masks in drugstores. Non-medical personnel may be more likely to buy expensive masks. Females, people living in the western region, and medical personnel may be more likely to know how to properly handle used masks and not to discard used masks at will. Medical personnel may be more likely to observe others discarding used masks at will.

Conclusion: In response to COVID-19, the public should be encouraged to use face masks and are advised not to reuse or throw away masks at will due to safety concerns.

Keywords: COVID-19, mask, epidemic outbreak

\section{Introduction}

The outbreak of coronavirus disease 2019 (COVID-19) began in Wuhan, China at the end of December 2019, ${ }^{1}$ and the ongoing COVID-19 epidemic poses a challenge for public health. Mounting evidence has shown that the outbreak is more widespread than was initially thought, and international spread via travelers has already occurred. ${ }^{2-4}$

Coronaviruses, which have single-stranded RNA genomes, belong to the family of Coronaviridae, and may cause respiratory and neurological diseases. ${ }^{5-7}$ Pneumonia resulting from COVID-19 infection mainly presents as a fever with respiratory symptoms, and is primarily spread by human-to-human transmission. ${ }^{8}$ Based on this, the Chinese government has encouraged people to wear masks in 
public places, such as supermarkets, places of entertainment and dining, conference rooms, and public streets and squares. Masks are an important protective tool, especially for travelers. ${ }^{9}$ However, during the spread of a respiratory infectious disease such as the COVID-19 pandemic, how to properly use and distribute masks deserves worldwide attention. $^{10}$

Masks have been considered as an essential commodity to prevent further spread of the COVID-19 pandemic. Due to the extreme shortage of personal protective equipment such as masks during the COVID-19 outbreak, ${ }^{11}$ the use of reusable cloth masks has become the focus of research. ${ }^{12}$ However, billions of single-use masks are currently being produced from petrochemical materials that do not quickly degrade after a single use, and without proper disposal, can cause environmental pollution and damage. ${ }^{13}$

In China and around the world, a majority of people are wearing face masks on the streets because of the COVID-19 outbreak. However, this practice has raised many questions, including whether there is a shortage of masks and how people discard used ones. Discarded masks can be found in many places, including buses, train stations, and streets. These issues are of concern, and the current status of mask shortages and mask disposal is unknown. Therefore, we designed and conducted a survey to investigate and ultimately address these issues in China, and to provide a preliminary experience for the widespread use of masks worldwide during the COVID-19 pandemic.

\section{Methods}

\section{Study Design, Population, and Sampling}

This survey was conducted from February 2, 2020 at 17:55:09 to February 4, 2020 at 19:22:05. A stratified random sampling method was used to conduct an anonymous cross-sectional online survey using the largest online survey platform in China, which is called Wen Juan Xing (Changsha Ranxing Information Technology Co., Ltd., Hunan, China). Wen Juan Xing, equivalent to Qualtrics, SurveyMonkey, or CloudResearch, provides online questionnaire design and survey functions for enterprises, research institutions, and individuals. The Wen Juan Xing sample database covers over 2.6 million respondents, whose personal information was confirmed, allowing for an authentic, diverse, and representative sample. The target population in the present study was Chinese adults living in Mainland China; thus, a random sample procedure stratified by age and location was adopted to match Chinese adults in the Wen Juan Xing sample database. A total of 2083 individuals responded to the questionnaire, which included two parts: basic information and questions. There were 41 invalid questionnaires (lack of information and incorrect data) that were eliminated, and 2042 valid questionnaires were finally included.

\section{Questionnaire Content Design}

Basic personal information included the respondents' age, sex, region, profession, and education level. The question section of the survey consisted of two components. The first component was designed to gather information regarding the public's behavior in the face of a mask shortage. It included the following three questions: (1) Do you reuse masks? (2) Have you purchased expensive masks? (3) Can you buy a mask at the local drugstore?

The second component was designed to gather information about whether the public knows how to correctly dispose of masks, as well as observations regarding the behavior of the public in dealing with discarded masks. It included the following four questions: (1) Do you know how to correctly dispose of used masks? (2) Have you thrown away your mask at will? (3) Have you seen someone throw away a mask at will? (4) Have you seen someone pick up a discarded mask? The respondents were divided into those from the western, central, and eastern regions of China (the divisions were chosen based on economic level).

\section{Statistical Analysis}

Percentages were calculated for the frequencies. The differences among groups were analyzed with chi-square tests. $\mathrm{P}<0.05$ was considered to indicate statistically significant differences. All statistics were processed with SPSS 24.0 software (SPSS Inc., Chicago, IL, USA).

\section{Data Sharing Statement}

All the data and materials mentioned in the manuscript are available.

\section{Ethics Approval and Consent to Participate}

The protocol of this study was approved by the research and ethics committee of Affiliated Hospital of Hangzhou Normal University. Information regarding the purpose of the study, voluntary nature of participation, and risk 
imposed due to involvement was presented in the information section of the survey. Informed consent forms were obtained from all participants. This study was conducted in accordance with the Declaration of Helsinki. Confidentiality of the information was maintained, and the data were recorded anonymously throughout the study.

\section{Results}

\section{Baseline Information}

The proportion of female respondents was higher than the proportion of male respondents. There were more respondents under 40 years of age than those over 40 years of age. The proportions of medical and non-medical personnel were basically the same. The number of respondents with a bachelor degree or above was greater than that with an education below a bachelor degree (Table 1).

\section{Public Response to the Questions Baseline of Response to the Questions}

Of the total number of respondents, $61 \%$ reported reusing masks, 32\% reported purchasing expensive masks, and only $19 \%$ reported being able to buy masks at their local drugstore (Figure 1). Additionally, 86\% of respondents reported knowing how to properly dispose of used masks, $7 \%$ reported having thrown away a used mask at will, and 50\% reported having seen someone else throw away a used mask at will (Figure 2).

Table I Baseline Characteristics of the Respondents

\begin{tabular}{|l|l|l|}
\hline & Num & Constituent Ratio (\%) \\
\hline $\begin{array}{l}\text { Gender } \\
\text { Male }\end{array}$ & 777 & $38 \%$ \\
Female & 1265 & $62 \%$ \\
\hline Age group(year) & & \\
$<40$ & 1398 & $68 \%$ \\
$\geq 40$ & 644 & $32 \%$ \\
\hline Profession & & \\
Medical staff & 1041 & $51 \%$ \\
Non-medical staff & 1001 & $49 \%$ \\
\hline Region & & \\
Eastern region & 825 & $40 \%$ \\
Western region & 605 & $30 \%$ \\
Central region & 612 & $30 \%$ \\
\hline Cultural level & & \\
Bachelor degree or above & 1599 & $78 \%$ \\
Below undergraduate level & 443 & $22 \%$ \\
\hline
\end{tabular}

\section{Repeated Use of Masks}

The number of respondents who reported the repeated use of masks in the central region was greater than that in the eastern and western regions $(P<0.05)$. The number of medical personnel who reported the repeated use of masks was greater than that of non-medical personnel $(P<0.05)$. There was no difference in the repeated and non-repeated use of masks between male and female respondents $(P>0.05)$ (Table 2).

\section{Buying Masks at the Local Drugstore}

Females, people living in the central region, and medical personnel were found to be less likely to buy masks at the local drugstore $(P<0.05)$ (Table 3$)$.

\section{Buying Expensive Masks}

Non-medical personnel were found to be more likely to buy expensive masks $(P<0.05)$ (Table 4$)$.

\section{Knowing How to Dispose of Used Masks}

Females, people living in the western region, and medical personnel were found to be more likely to know how to properly dispose of used masks $(P<0.05)$ (Table 5$)$.

\section{Throwing Away Used Masks at Will}

Females, people in the western region, and medical personnel were found to be less likely to throw away used masks at will $(P<0.05)($ Table 6$)$.

\section{Observing Someone Throwing Away a Used Mask at Will}

Medical personnel were found to be more likely to have observed someone throw away a used mask at will $(P<0.05)$ (Table 7).

\section{Discussion}

It is necessary to wear a mask when respiratory infectious diseases are prevalent, because masks play an important role in the protection of the individual. ${ }^{14-17} \mathrm{~A}$ study showed that surgical masks reduce virus detection in large respiratory droplets and in aerosols, suggesting that the use of surgical face masks by infected patients will reduce virus transmission. ${ }^{17}$ However, not all people are willing to wear masks. Although the prevalence rate of face mask use was fairly low in places such as Ahvaz, Iran, ${ }^{18}$ the government has made it mandatory to wear masks in public in China. As the COVID-19 outbreak progressed, people rushed to buy masks, and they quickly became scarce. ${ }^{19}$ Thus, this survey was conducted to investigate mask shortages and mask disposal in China. 

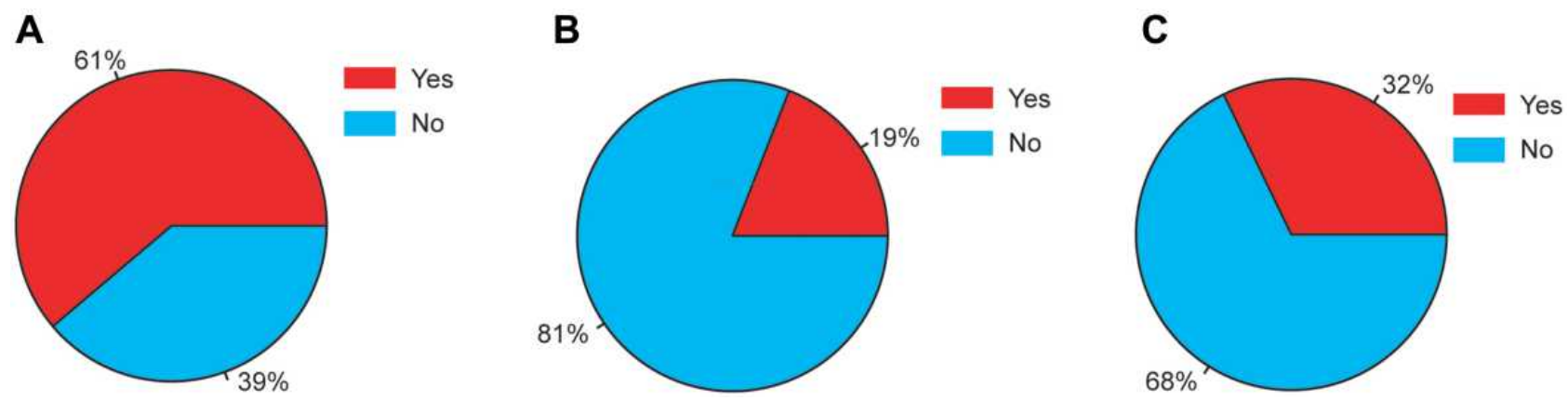

Figure I Pie chart showing answers. (A) Constituent ratio of reusing masks is 61\%; (B) Constituent ratio of obtaining masks at the local pharmacy is I9\%; (C) Constituent ratio of buying expensive masks is $32 \%$.

Notes: (A) Whether to reuse the mask? (B) Can you get masks at the local pharmacy? (C) Do you buy expensive masks? The respondent should supply one answer, yes or no.
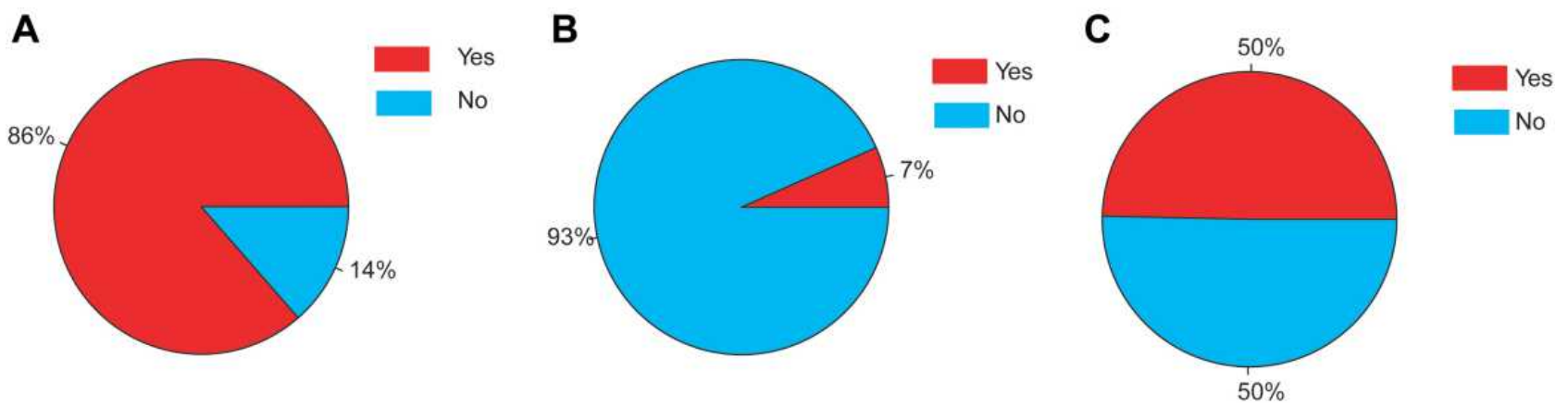

Figure 2 Pie chart of answers. (A) Constituent ratio of knowing what to do with the used mask is $86 \%$; (B) Constituent ratio of discarding the used masks by themselves at will is $7 \%$; (C) Constituent ratio of observing others throw away their used masks is $50 \%$.

Notes: (A) Do you know how to deal with used masks the correct way? (B) Have you thrown away your mask at will? (C) Do you see people discarding their masks at will? The respondent should supply one answer, yes or no.

In this investigation, it was found that the constituent ratio of the respondents who reuse masks was $61 \%$. Additionally, our investigation shows that obtaining masks from a local drugstore was reported to be very difficult, and approximately $1 / 3$ of the respondents purchased expensive masks. It is unclear here whether respondents purchased expensive masks because the less costly masks were constantly out of stock in drugstores, and the expensive masks were the only ones available, or whether these respondents did not feel that the inexpensive masks offered sufficient protection and were willing to pay more to buy an expensive mask that provided a more solid barrier against the virus.

Additionally, most respondents know how to properly dispose of used masks, and only $7 \%$ have casually discarded masks. However, $50 \%$ of respondents have seen others discarding used masks at will. The survey results indicate that there is a current shortage of masks. China has a population of 1.4 billion. Assuming that $2 / 3$ of the people in China must wear a mask every day, the daily demand for masks will reach 900 million. However, this particular epidemic breakout occurred during the Spring Festival, when the mask factory was closed and the factory workers were on vacation. Although some workers have returned to work because of the government's appeal, the factory is far from reaching $100 \%$ of its production capacity, and masks therefore remain in short supply. Because of this imbalance between supply and demand, it is difficult for people to buy masks at drugstores because they are not in stock, and as a result, some people have purchased expensive masks.

Further analysis revealed some very interesting differences among the respondents. Females, people living in the central region, and medical personnel may have more difficulty in obtaining masks from drugstores, and nonmedical personnel may be more likely to buy expensive masks. Additionally, respondents in the central part of China tend to use masks repeatedly, as do medical personnel. These findings indicate that healthcare workers are more likely to be mask-deficient and must therefore resort 
Table 2 Differences in Gender, Region and Occupation Between Repeated Use and Non-Repeated Use of Masks. The Number of People with Repeated Use of Masks in Central Region Was More Than These in Eastern Region and Western Region $(P<0.05)$; the Number of Medical Staff with Repeated Use of Masks Was More Than That of Non-Medical Staff $(P<0.05)$. There Was No Difference Between Male and Female $(P>0.05)$

\begin{tabular}{|c|c|c|c|c|}
\hline Variable & Yes & No & $\mathbf{x}^{2}$ & $P$ value \\
\hline Sex & & & 1.01 & 0.31 \\
\hline Male & $464(59.7 \%)$ & $313(40.3 \%)$ & & \\
\hline Female & 785(57.5\%) & $580(42.5 \%)$ & & \\
\hline Region & & & 49.28 & $P<0.05$ \\
\hline Eastern region & $483(58.5 \%)$ & $342(41.5 \%)$ & & \\
\hline Western region & $328(53.6 \%)$ & $284(46.4 \%)$ & & \\
\hline Central region & $438(72.4 \%)$ & $167(27.6 \%)$ & & \\
\hline Profession & & & 100.82 & $<0.05$ \\
\hline Medical staff & $719(69.1 \%)$ & $322(30.9 \%)$ & & \\
\hline Non-medical staff & $47 \mid(47.1 \%)$ & $530(52.9 \%)$ & & \\
\hline
\end{tabular}

Note: Do you reuse masks? The answer is yes or no.

to wearing the same mask multiple times. In Wuhan, China, the center of the epidemic, masks may be far scarcer.

Another important question is how to dispose of used masks. Most of the respondents reported that they know how to dispose of used masks and would not throw away used masks at will. However, $50 \%$ of the respondents reported having seen someone throwing away a used mask at will. Such an outcome indicates that there are many people who do not know what to do with their used masks. In the analysis of subgroups, medical personnel

Table 3 Differences in Gender, Region and Occupation Between Getting the Masks and Not Getting the Mask in Drugstore. Female, the People Living the Central Region and Medical Staff May Be More Likely to Be Unable to Buy a Mask $(P<0.05)$

\begin{tabular}{|c|c|c|c|c|}
\hline Variable & Yes & No & $x^{2}$ & $P$ value \\
\hline Sex & & & 16.02 & $<0.05$ \\
\hline Male & $183(23.6 \%)$ & $594(76.4 \%)$ & & \\
\hline Female & $206(16.3 \%)$ & $1059(83.7 \%)$ & & \\
\hline Region & & & 29.245 & $<0.05$ \\
\hline Eastern region & $153(18.5 \%)$ & 673 (81.5\%) & & \\
\hline Western region & $156(25.4 \%)$ & 456 (74.6\%) & & \\
\hline Central region & 81 (13.4\%) & $524(86.6 \%)$ & & \\
\hline Profession & & & 331.04 & $<0.05$ \\
\hline Medical staff & $158(15.2 \%)$ & $883(84.8 \%)$ & & \\
\hline Non-medical staff & $23 \mathrm{I}(23.4 \%)$ & $770(76.6 \%)$ & & \\
\hline
\end{tabular}

Note: Can you get masks at the local pharmacy? The answer is yes or no.
Table 4 Differences in Gender, Region and Occupation Between Buying the Expensive Masks and Not Buying Expensive the Mask in Drugstore. Non-Medical Staff May Be More Likely to Be Buy an Expensive Mask $(P<0.05)$

\begin{tabular}{|l|l|l|l|l|}
\hline Variable & Yes & No & $\mathbf{X}^{\mathbf{2}}$ & P value \\
\hline Sex & & & 4.00 & 0.05 \\
$\quad$ Male & $229(29.5 \%)$ & $548(70.5 \%)$ & & \\
Female & $428(33.8 \%)$ & $837(66.2 \%)$ & & \\
\hline Region & & & 3.5965 & 0.17 \\
Eastern region & $283(34.3 \%)$ & $542(65.7 \%)$ & & \\
Western region & $195(31.8 \%)$ & $417(68.2 \%)$ & & \\
Central region & $179(29.6 \%)$ & $426(70.4 \%)$ & & \\
\hline $\begin{array}{l}\text { Profession } \\
\text { Medical staff } \\
\text { Non-medical staff }\end{array}$ & $309(29.7 \%)$ & $732(70.3 \%)$ & & \\
\hline
\end{tabular}

Note: Do you buy expensive masks? The answer is yes or no.

Table 5 Differences in Gender, Region and Occupation Between Knowing to Deal with the Used Masks and Not Knowing to Do That. Female, the People Living in Western Region and Medical Staff May Be More Likely to Know to Deal with the Used Masks Bye the Right Way $(P<0.05)$

\begin{tabular}{|c|c|c|c|c|}
\hline Variable & Yes & No & $x^{2}$ & $P$ value \\
\hline Sex & & & 42.71 & $<0.05$ \\
\hline Male & $622(80.0 \%)$ & $155(20.0 \%)$ & & \\
\hline Female & $1143(90.3 \%)$ & $122(9.7 \%)$ & & \\
\hline Region & & & 18.53 & $<0.05$ \\
\hline Eastern region & $700(84.9 \%)$ & $125(15.1 \%)$ & & \\
\hline Western region & $553(91.1 \%)$ & $52(8.9 \%)$ & & \\
\hline Central region & $512(84.2 \%)$ & $100(15.8 \%)$ & & \\
\hline Profession & & & 111.59 & $<0.05$ \\
\hline Medical staff & $982(99.5 \%)$ & $59(0.5 \%)$ & & \\
\hline Non-medical staff & $783(78.2 \%)$ & $218(21.8 \%)$ & & \\
\hline
\end{tabular}

Note: A: Do you know how to deal with used masks by the right way? The answer is yes or no.

were found to be more likely to have observed such behavior. In fact, it was found that many used masks were discarded in different places, such as buses, train stations, hospitals, and streets. ${ }^{20}$ These discarded masks may cause secondary infections, which is a foremost concern. A recent study has shown that incorrect mask treatment may increase the infection rate. ${ }^{17}$ From the findings of the present survey, it is evident that medical personnel are more careful about the disposal of used masks, and this may be because they have health and financial incentives to do so.

Therefore, the proper disposal of discarded masks should be actively promoted, and the public should be encouraged to not throw away masks at will. The 
Table 6 Differences in Gender, Region and Occupation Between Throwing the Mask at Will by Themselves and Not Throwing the Used Masks at Will. Female, the People in Western Region and Medical Staff May Be More Likely to Be Unable to Throw the Used Masks at Will $(P<0.05)$

\begin{tabular}{|l|l|l|l|l|}
\hline Variable & Yes & No & $\mathbf{X}^{2}$ & $P$ value \\
\hline $\begin{array}{l}\text { Sex } \\
\text { Male }\end{array}$ & $66(8.5 \%)$ & $\begin{array}{l}711(91.5 \%) \\
1196(94.5 \%)\end{array}$ & 6.72 & 0.001 \\
Female & $69(5.5 \%)$ & \\
\hline $\begin{array}{l}\text { Region } \\
\text { Eastern region } \\
\text { Western region } \\
\text { Central region }\end{array}$ & $\begin{array}{l}62(7.5 \%) \\
53(8.6 \%)\end{array}$ & $\begin{array}{l}763(92.5 \%) \\
585(96.7 \%)\end{array}$ & & \\
\hline $\begin{array}{l}559(91.4 \%) \\
\text { Profession }\end{array}$ & & & \\
Medical staff & $47(4.5 \%)$ & $994(95.5 \%)$ & & \\
Non-medical staff & $88(8.8 \%)$ & $913(91.2 \%)$ & & \\
\hline
\end{tabular}

Note: Have you thrown away your used mask at will? The answer is yes or no.

Table 7 Differences in Gender, Region and Occupation Between Finding Throwing the Used Masks by Others and Not Finding Throwing the Used Masks by Others. Medical Staff May Be More Likely to Find the Others to Throw the Used Masks $(P<0.05)$

\begin{tabular}{|c|c|c|c|c|}
\hline Variable & Yes & No & $x^{2}$ & $P$ value \\
\hline Sex & & & 0.023 & 0.879 \\
\hline Male & 388 (49.9\%) & 389 (50.1\%) & & \\
\hline Female & $626(49.4 \%)$ & 639 (50.6\%) & & \\
\hline Region & & & 1.74 & 0.43 \\
\hline Eastern region & $4 \mid 3(50.6 \%)$ & $412(49.4 \%)$ & & \\
\hline Western region & $310(51.2 \%)$ & $295(48.8 \%)$ & & \\
\hline Central region & $291(47.5 \%)$ & $321(52.5 \%)$ & & \\
\hline Profession & & & 94.12 & $<0.05$ \\
\hline Medical staff & $627(60.2 \%)$ & 414 (39.8\%) & & \\
\hline Non-medical staff & 387 (38.7\%) & $614(61.3 \%)$ & & \\
\hline
\end{tabular}

Note: Do you see people throwing masks at will? The answer is yes or no.

government should also make the appropriate recommendations for mask disposal. Recycling bins for masks should be placed in public areas, and should be very eyecatching with a prominent logo to help the public quickly identify them.

The Chinese government has taken many measures to solve this problem. Our survey was conducted at the peak of the COVID-19 outbreak in China. The rapid control of the COVID-19 epidemic in China has been due to various efforts. Face masks are an important aspect of effective prevention and control of the COVID-19 epidemic. We hope that the results of this survey can provide valuable experience and lessons for other prevention and control efforts in the world, so as to achieve the goal of controlling the spread of the COVID-19 epidemic.

\section{Acknowledgments}

We thank EditorBar (https://www.editorbar.com/) for editing this manuscript.

\section{Author Contributions}

All authors made substantial contributions to conception and design, acquisition of data, or analysis and interpretation of data; took part in drafting the article or critically revising it for important intellectual content; agreed to submit to the current journal; gave final approval for the version to be published; and agreed to be accountable for all aspects of the work.

\section{Funding}

The presented study was supported by Hangzhou Science and Technology Bureau fund (No.20150733Q24; No. 20191203B96; No. 20191203B105; No. 20171334M01); Youth Fund of Zhejiang Academy of Medical Sciences (No. 2019Y009); Medical and Technology Project of Zhejiang Province (No.2020362651;No. 2021KY890); Clinical Research Fund of Zhejiang Medical Association (No.2020ZYC-A13); Hangzhou Health and Family Planning Technology Plan Key Projects (No.2017ZD02).

\section{Disclosure}

The authors declare that they have no competing interests.

\section{References}

1. Zhu N, Zhang D, Wang W, et al. A novel coronavirus from patients with pneumonia in China, 2019. N Engl J Med. 2020;382(8):727-733. doi:10.1056/NEJMoa2001017

2. Hui DS, Azhar I, Madani TA, et al. The continuing 2019-nCoV epidemic threat of novel coronaviruses to global health - the latest 2019 novel coronavirus outbreak in Wuhan, China. Int J Infect Dis. 2020;91:264-266. doi:10.1016/j.ijid.2020.01.009

3. Backer JA, Klinkenberg D, Wallinga J. Incubation period of 2019 novel coronavirus (2019-nCoV) infections among travellers from Wuhan, China, 20-28 January 2020. Euro Surveill. 2020;25 (5):2000062. doi:10.2807/1560-7917.ES.2020.25.5.2000062

4. Wu JT, Leung K, Leung GM. Nowcasting and forecasting the potential domestic and international spread of the 2019-nCoV outbreak originating in Wuhan, China: a Modelling Study. Lancet. 2020;395 (10225):689-697. doi:10.1016/S0140-6736(20)30260-9

5. Corman VM, Eckerle I, Bleicker T, et al. Detection of a novel human coronavirus by real-time reverse-transcription polymerase chain reaction. Euro Surveill. 2012;17(39):20285. doi:10.2807/ese.17.39. 20285-en

6. Huang P, Wang H, Cao Z, et al. A rapid and specific assay for the detection of MERS-CoV. Front Microbiol. 2018;9:1101. doi:10.3389/ fmicb.2018.01101 
7. Zaki AM, van Boheemen S, Bestebroer TM, et al. Isolation of a novel coronavirus from a man with pneumonia in Saudi Arabia. $N$ Engl J Med. 2012;367(19):1814-1820. doi:10.1056/NEJMoa 1211721

8. Lu H. Drug treatment options for the 2019-new coronavirus (2019-nCoV). Biosci Trends. 2020;14(1):69-71. doi:10.5582/ bst. 2020.01020

9. Chiodini J. Maps, masks and media - traveller and practitioner resources for 2019 novel coronavirus (2019-nCoV) acute respiratory virus. Travel Med Infect Dis. 2020;33:101574. doi:10.1016/j. tmaid.2020.101574

10. Zhang T, Wang Q, Shi W, et al. Achieving universal wearing of face masks during the COVID-19 pandemic: a practical solution from Shanghai, China. Risk Manag Healthc Policy. 2020;13:3067-3077. doi:10.2147/RMHP.S280672

11. Nogee D, Tomassoni AJ. Covid-19 and the N95 respirator shortage: closing the gap. Infect Control Hosp Epidemiol. 2020;41(8):958. doi:10.1017/ice.2020.124

12. Bhattacharjee S, Bahl P, Chughtai AA, et al. Last-resort strategies during mask shortages: optimal design features of cloth masks and decontamination of disposable masks during the COVID-19 pandemic. BMJ Open Respir Res. 2020;7(1):e000698. doi:10.1136/ bmjresp-2020-000698

13. Das O, Neisiany RE, Capezza AJ, et al. The need for fully bio-based facemasks to counter coronavirus outbreaks: a perspective. Sci Total Environ. 2020;736:139611. doi:10.1016/j. scitotenv.2020.139611
14. Rajakaruna SJ, Liu WB, Ding YB, et al. Strategy and technology to prevent hospital-acquired infections: lessons from SARS, Ebola, and MERS in Asia and West Africa. Mil Med Res. 2017;4(1):32. doi:10.1186/s40779-017-0142-5

15. MacIntyre CR, Wang Q. Physical distancing, face masks, and eye protection for prevention of COVID-19. Lancet. 2020;395 (10242):1950-1951. doi:10.1016/S0140-6736(20)31183-1

16. Blanco N, Eisenberg MC, Stillwell T, et al. What transmission precautions best control influenza spread in a hospital? Am J Epidemiol. 2016;183:1045-1054. doi:10.1093/aje/kwv293

17. Scalvenzi M, Villani A, Ruggiero A, Wigington T, Noonan D, Simmons LA. Community knowledge about the use, reuse, disinfection and disposal of masks and filtering facepiece respirators: results of a study conducted in a dermatology clinic at the University of Naples in Italy. J Community Health. 2020;45(1):1-8. doi:10.1007/ s10900-020-00952-3

18. Rahimi Z, Shirali GA, Araban M, et al. Mask use among pedestrians during the Covid-19 pandemic in Southwest Iran: an observational study on 10,440 people. BMC Public Health. 2021;21(1):133. doi:10.1186/s12889-020-10152-2

19. Wang MW, Zhou MY, Ji GH, et al. Mask crisis during the COVID-19 outbreak. Eur Rev Med Pharmacol Sci. 2020;24(6):3397-3399. doi:10.26355/eurrev 20200320707

20. Wang MW, Cheng YR, Ye $\bar{L}$, et al. The COVID-19 outbreak: the issue of face masks. Infect Control Hosp Epidemiol. 2020;41 (8):974-975. doi:10.1017/ice.2020.129
Risk Management and Healthcare Policy

\section{Publish your work in this journal}

Risk Management and Healthcare Policy is an international, peerreviewed, open access journal focusing on all aspects of public health, policy, and preventative measures to promote good health and improve morbidity and mortality in the population. The journal welcomes submitted papers covering original research, basic science, clinical \& epidemiological studies, reviews and evaluations, guidelines, expert opinion and commentary, case reports and extended reports. The manuscript management system is completely online and includes a very quick and fair peer-review system, which is all easy to use. Visit http://www.dovepress.com/testimonials.php to read real quotes from published authors. 